\title{
RAPID APPRAISAL FOR RURAL DEVELOPMENT
}

\author{
IAN CARruthers \\ Agrarian Development Unit, Wye College, \\ Near Ashford, Kent TN25 5AH, Great Britain \\ $\&$ \\ Robert Chambers \\ Institute of Development Studies, University of Sussex, \\ Brighton, Sussex BN1 9RE, Great Britain
}

(Received: 22 December, 1980)

NEED AND RATIONALE

Almost all those concerned with rural development research, policy and practice have insufficient resources, including time, to enable them to produce work which fully satisfies the professional criteria they set themselves. In tackling development problems rapid appraisal of rural situations is inevitably forced upon government officials, workers in voluntary agencies, researchers and aid agency staff. Whether these investigators are administrators, technical specialists such as doctors, agriculturists and soil scientists, social scientists. or politicians they need to consider, develop and adopt short cut approaches to collecting and scrutinising evidence.

Short cut methods do not have to be second rate and unprofessional. Indeed, if given thought, they can be effective and efficient. The papers in this special issue of Agricultural Administration illustrate how some rural development workers have approached their task of economising in the use of scarce resources for rural investigations. In this introductory paper we wish to broaden the discussion to include more general aspects, key principles, obstacles to improved methods and alternative methods for rapid appraisal.

\section{TWO CULTURES}

In rural development and rural research, there is a tension between two approaches to understanding: that of the academic community, interested more in detail, precise observation and measurement and rigorous and respectable methodology and with a generally rather unhurried concern with knowledge for its own sake in the longer term (for example these papers, the original versions of which were written in 1979, emerge in published form only in 1981) and that of practitioners, concerned more 407

Agricultural Administration 0309-586X/81/0008-0407/\$02.50 (C) Applied Science Publishers Ltd, England, 1981

Printed in Great Britain 
with overviews and orders of magnitude, prepared to improvise and make do with data sources and tied to deadlines which focus on knowledge needed in the shorter term. The two cultures-academic and practical-are sometimes separated by mutual incomprehension much as were the two cultures-scientific and literary-on which C. P. Snow remarked in $1959 .{ }^{13} \mathrm{But}$, as in that case, the separation is unfortunate, with losses on both sides. Academics drift off into intellectually titillating trivia, muttering in private languages to more refined, but smaller and smaller audiences and practitioners become naive philistines who see no further than the ends of their noses, with a false confidence in their judgements and a growing distrust of theory or even evidence. Academics would often benefit from the discipline and responsibility of operating more in the real, time-bound world and practitioners, for their part, would often benefit from insights into what is less obvious and from the challenges which would emerge from a deeper and broader understanding of change.

In rural development, this polarisation is exemplified in the manner in which professionals find out about rural situations. In its stereotype the academic approach is meticulous and rigorous, with a scientific respect for evidence and a certain timelessness. The social anthropologist spends one or two years in a village, recording almost everything and may spend the remainder of a lifetime writing it up; or the sociologist or agricultural economist mounts an extensive questionnaire survey, the processing of which takes years, often extended by a period of fascination with computers or some analytical technique; or the agricultural scientist on a research station and in a laboratory steadily explores relationships and long-term trends, or develops new varieties, slowed by the steady rhythm of the seasons. In contrast, the practitioner wants quick insights and quick results. Brief rural visits, snatches of information here and there and a few observations, anecdotes and impressions are put together as the basis for time-bound judgements and decisions. The files must be kept moving and decisions made and only a crude rationale may be necessary to support a chosen line.

The middle ground between these two approaches has been a no man's land. For the academic, there are professional risks in straying from the straight and narrow paths of conventional methodology. Wood ${ }^{26}$ puts the accademic case when he states that he is suspicious of 'shortcuts, hunches, skinny surveys, rural development tourism and other methodological demons'. So are we all. But, as he says, rapid rural appraisal (RRA) is preferable to the pure prejudice and preconviction which are so often the basis for action. For the practitioner, on the other hand, there may seem little to be gained from trying to meet immediate practical needs with the slowmoving approaches of long-term research. In the field of rural development over the past decade, the tension between these two extremes has converged on the middle ground, with a search for methods of finding out about rural situations which are quicker and so, for practical purposes, more cost-effective. Belshaw ${ }^{31}$ has explored the theoretical foundations of data economising approaches and in health and 
nutrition (Gordon, ${ }^{45}$ Hay, ${ }^{47}$ Pacey, ${ }^{9,10}$ Payne, ${ }^{58}$ Walker $^{64}$ and $\mathrm{WHO}^{16}$ ), socioeconomic stratification (Honadle, ${ }^{50}$ Howes $^{52}$ and Longhurst ${ }^{53}$ ) and project identification and appraisal (Bridger, ${ }^{34}$ Ellman, ${ }^{41}$ OXFAM, ${ }^{8}$ Pacey, ${ }^{9}$ Stares ${ }^{60}$ and Taylor ${ }^{63}$ ) attempts have been made to take stock of practices already developed and to explore others. What began as illicit colonisation of the no man's land is becoming, we hope, much more a legitimate form of settlement.

\section{SCOPE AND FUNCTION}

Techniques for RRA are not put forward as substitutes either for scholarly work or for long-term studies, but as complements to existing methods of enquiry. The papers in this issue demonstrate that they can offer a professional approach and that 'quick and dirty' methods can be improved and made cost-effective in terms of personnel, finance and time.

The phrase 'rapid rural appraisal' should be interpreted broadly. It is not at all limited to project appraisal, although RRA is used for that. It can have many purposes, including assessment of rural conditions and social relationships and monitoring and evaluation. Two purposes which are particularly time-bounded are the appraisal of emergencies and gathering data for decisions (on agricultural prices, on input supplies, on agricultural subsidies, and so on) which have deadlines determined by the seasons or by budget cycles. The papers in this issue are relevant to these purposes, but they are especially concerned with the investigation of natural resources, their utilisation and changes in them over time (see the papers by Stocking and Abel and by Swift); the appraisal of local conditions and farming systems and the identification of priorities and programmes for agricultural research and farmer innovation (see the papers by Hildebrand, by Collinson and by Bartlett and Ikeorgu) and project identification and development (Ellman). These illustrate some of the potential applications of RRA in rural research and assessment. There are many more.

We should be well aware of dangers inherent in any attempt to lend undue respect to RRA. If time and resources were unlimited, it would be an imperfect approach. There is always the danger that RRA will be restricted to providing a detailed rationale for a particular ideology, confirming or rejecting partial hypotheses. Without an open, questioning approach, RRA may simply legitimate a politically determined proposal, fail to refute false knowledge, fail to discover an alternative, often more complicated, explanation, or divert attention from the need for longterm studies (Wood ${ }^{26}$ Richards $^{59}$ ). In short, it may simply help sponsors go wrong sooner with greater confidence. The outcome of RRA may then be to give a false or spurious air of efficiency or precision in policy matters.

To be aware of such dangers is, to our mind, a precondition for successful RRA. Our veneer of knowledge of the process of rural development is very thin. Policies 
and projects (and even so-called theories) are often based upon very few, crude and unreliable empirical studies. Nevertheless, even in the face of ignorance, resources have to be deployed and decisions have to be made. The purpose of these papers is to show that fieldwork procedures currently used to assist this decision-making process can be improved and that new methods can he productive; that it is possible for open minds to receive fresh insights and different perspectives and that prior knowledge and theoretical or ideological boundaries need not always be a constraint to fresh ideas or valid interpretations of evidence.

In December, 1979 a conference was held at the Institute of Development Studies with the purpose of comparing ideas, arguments, evidence and practical experience with RRA in different fields, so that its prevalence, methods, potential and limitations could be better understood and its practice improved. (For reviews of the conference see Alderson, ${ }^{70}$ and Conlin and Wiggins ${ }^{73}$ and for RRA more generally see Barnett, ${ }^{29}$ Chambers $^{4}$ and Pacey ${ }^{9}$ ). The questions considered included: to what extent, for what purposes, in what conditions, and with what methods, could RRA be made cost-effective or quick-and-clean? What were the trade-offs, in what circumstances, between quantity, accuracy, relevance, timeliness and beneficial use of information? Could methods and experience in one field be adapted and transferred to another? Should RRA be discouraged or developed? And if developed, how? The papers in this issue were case studies presented to illuminate these issues.

\section{PRINCIPLES}

In determining appropriate methods and intensities of investigation, judgements need to be made on the amount, accuracy, relevance, timeliness and practical utility of information required. Information which is unnecessary or unheeded is a luxury. Two of the most important concepts for establishing the appropriate level of information are opportunity cost and trade-off. The opportunity cost of the benefits gained by spending three months on a village case study are the benefits foregone by, for example, not conducting a more superficial cross-sectional survey of a number of villages or a desk study of existing literature on villages. If a richer understanding of the complex interrelationships within a village are obtained from a case-study, but a better appreciation of inter-village variations and the representativeness of any one village emerge from a cross-sectional study, then, in selecting means for investigation, there is a trade-off to be struck between the depth and the context of the knowledge. In our view, issues relating to opportunity cost and trade-off arise in all areas of enquiry but most markedly in the context of sampling, as discussed later.

Desire for professionalism tends to encourage those concerned with rural development to search in the direction of the exhaustive explanation. For a 
professional to fall too far short of this state is considered unsatisfactory. However, this goal is an unreachable illusion for practitioners and an unreasonable goal for academics. In its place there is much to commend what Ilchman ${ }^{7}$ terms 'optimal ignorance' where a person, for example a planner, asks what need not be known and judges knowledge simply in terms of its efficiency for decisions. Ilchman goes further in suggesting that, in low income countries, pursuit of the exhaustive explanation contributes to what he terms 'intellectual neo-colonialism'. This is the ability of some with an apparent monopoly of intellectual skills (and jargon) to hold others in subjugation either directly or indirectly by diminishing their confidence in their mastery. The views and advice emanating from the Sussex Conference and explored in these papers may not eliminate such tendencies; but we hope that field workers will consider how methods can be improved to a state of optimal ignorance, and will recognise that RRA, properly used can be liberating and is not a second best. To the contrary, by being cost-effective in its trade-offs, it should raise professional standards to a new level.

In the 1970's slow growth rates of agricultural production (about $2.6 \%$ per year) and depressingly poor performance on special rural development projects have emphasised how tangled and difficult the task is and how urgent it now is to have more success. Specialists have recognised the limits of their competence and physical and social scientists have given each other a heightened - if somewhat grudgingrespect. A holistic or systems view of rural problems is seen to be necessary and desirable. Multi-disciplinary investigations are in favour. Unfortunately, realisation that the problems are more intricate and that more disciplines are relevant has not generally enabled executing agencies to obtain proportionate increases in resources for investigation. Broadening of remits has then to be at the cost of the core of conventional investigations. Under pressure of urgency, with limited resources and subject to the demands of more disciplines, investigating teams need all the more to apply the principle of optimal ignorance and to make wise use of RRA techniques.

Paradoxically, short-cut procedures are more and not less demanding of expertise, and optimal ignorance can only be achieved if investigators are both well informed and sensitive to what they may not know. In their search for rapidity, they should not neglect complexity. Rural life is perplexing to study, especially when time is short. For example, there are seasonal peaks and troughs in sickness, nutrition status, workload, prices of products, demands for credit, ability to travel and so forth. In addition, there is a year effect with good and bad years. A researcher engaged on a rapid rural appraisal may not be able to select the year-or even the month - of investigation but must be able to formulate appropriate questions and to interpret what is seen and heard both for other times of the year and for other years.

In untrained imprudent hands RRA can mislead. The quick questionnaire can impose categories and meanings on a reality with which it may not correspond. The questioner in a hurry does not have time to learn from the respondent's constructs 
and ways of seeing things. Meanings are blunted and distorted in translation and in the translator's own interpretations. A major problem is remaining open to, and recognising, the unknown - in Paul Richards' terms, ${ }^{22}$ knowing how to identify the questions one does not know to ask. The need here is to put the 'search' back into research, to notice and follow up on the unexpected, on the new practice which farmers have developed for themselves on the illuminating comment casually dropped by a respondent' $\left(\right.$ Eyben $^{42}$ ). For social anthropologists this is nothing new:

$\therefore$...the fieldworker cannot anticipate the developments in the field which will inevitably guide the course of his investigations. Hypotheses formed without regard to these considerations may turn out to be trivial, if not banal...'

(Srinivas et $a .^{15}$ p.8)

It has, however, been in multi-disciplinary work in agricultural economics and agronomy and, to a lesser extent, involving sociology and social anthropology, that the greatest inventiveness and fastest progress has been made. Agricultural economists are emerging from a period of preoccupation with individual crops, analytical techniques and elegant models with unrealistic assumptions. One current focus is with crop combinations and farming systems. The analytical techniques such as production function analysis, linear programming and simulation are employed as much to discipline thinking about the problems as for the numbers on the computer print out. Agricultural economists are disciplinary specialists and, in consequence, their models are now more alluring but less amenable to quantification. Even the most severe neo-classical theorists grudgingly concede a growing rôle for political economy. The rag-bag labelled 'social factors' is being peered into and interesting items drawn out into the light. In this context, rapid rural appraisal techniques are 'appropriate technology'; it means quite simply to find out what is happening in rural areas - discovering that farmers are often right and extension workers wrong, learning that sometimes farmers are ahead of science (Brammer ${ }^{1}$ ) and able to educate researchers, and appreciating more the nature and discipline of seasonal interactions (Pacey et al. ${ }^{10}$ ). In short, a broader, more open, curious and modest approach to investigation is being adopted by practitioners of RRA and this is illustrated in the papers in this issue. Although it would not be strictly true to describe these authors as pre-theoretical, they are less tied to one ideology, perspective or discipline than some critics (Richards ${ }^{22.59}$ ) might allow.

The innovations, illustrated here by Collinson, Hildebrand and Bartlett and Ikeorgu, are a creative response to pressures for cost-effectiveness in rural appraisal. For parctical purposes, this implies optimising the trade-offs between quantity, accuracy, relevance, timeliness and actual use of information. For 'costeffectiveness' can be misleading if it is taken to imply merely some putative mathematical ratios in trade-offs. It also entails alertness, observation, imagination and the ability to pursue serendipity. 
TIMELINESS

It is, however, timeliness that we wish especially to emphasise for it is the main pressure providing impetus for change. The adage from music publishing that it doesn't have to be good, but get it to me by Tuesday' is an extreme example of the importance of timeliness and a good illustration of a trade-off. In agriculture, seasons dictate a sequence of activities, often with little flexibility. For example, slight deviation from optimal planting date can have a disproportionate impact upon ultimate crop yield. With government agencies servicing agriculture, the efficiency of most decisions is time-linked in some way, with the value of the information a declining function of time. For example, decisions on input prices or product support prices have to be made in advance of sowing if they are to be fully effective. A higher than anticipated price for rice announced after sowing dates on the basis of a late delivered but thorough field survey of depleted grain stocks can result in farmer response through better weeding, more precise irrigation and more fertiliser but it will be too late to affect the more powerful determinants of crop production. These include area cropped, quality of the selected soil, and seedbed preparation. The opportunity to respond is simply not open to famers if advice or incentives are untimely.

The need for timely information has, however, often been met in an unself-critical and unrigorous manner. The casual empiricism of rural development tourism-the phenomenon of brief rural visits by urban-based professionals - is subject to many biases (Chambers ${ }^{5}$ ), pointing towards more accessible and more prosperous rural environments and people. The biases have dimensions which are spatial (urban, peri-urban, prosperous region, tarmac, roadside and the centre, not the periphery, of the village), project (visits to projects with special treatment, not the spaces where there are no projects), person (contact with the rural elite, men rather than women, adopters rather than non-adopters, users of scrvices rather than non-users) and seasonal (in the healthier, better fed dry season, not the hungry, sick wet season). They also emphasise what is visible, the neglect of social relationships, and present glimpses at one point in time which do not reveal trends.

\section{APPROPRIATE PRECISION}

Failure to appreciate the crucial importance of timeliness can cause much professional work to be wasted. This is well illustrated in the case of investigations leading to detailed project feasibility plans. Few project planners appear fully to apprcciatc how carly in the planning process the form of the project is fixed. Most agricultural projects require several disciplines for effective planning and design. The work of all team members is normally linked in a systematic way and, to varying 
extents, one team member requires the outcome of another's work in order to initiate his or her own. Thus, for example, at the beginning of the investigation for an irrigation project the agriculturist requires data on crop water requirements from the crop physiologist as an input in assessing feasible crop water requirements. The crop physiologist, for his or her part, needs information on the likely range of crops, which is dependent upon data from, among others, soil scientists and economists. The agriculturist, in defining the likely crop mix and cropping intensity, needs to know the water availability in, say, ten-day periods over the ycar. But the engincers cannot answer this question until they have information on river flows and groundwater availability and the levels of cost the project can bear. This will depend, among other things, upon crop production. Again, the farm management economist, with interest in labour and farm power requirements over the year, will attempt to establish the economic feasibility of the selected crop mix. But the crop mix cannot be determined until water availability over time has been ascertained. Each specialist has thus to wait for the work of others.

In practice, one of two solutions to this dilemma is adopted. The first is for team members to try to obtain advance judgements from their colleagues. In practice, our experience has been that practitioners in some disciplines are more reluctant to make advance estimates of orders of magnitude than others. Agronomists, for example, usually hesitate to forecast future farm-level crop yields. But if specialists cannot or will not make such estimates, then others who depend on them are forced to invent their own, so that their work is founded on the weak base of unprofessional and uninformed guesstimates. Moreover, crude assumptions of this sort quickly 'set' and are built into the structure of assumptions and acquire a quite spurious authority.

The sccond solution is for the project management to determine, tentatively, central working assumptions on which specialists can base their preliminary work programmes. This also has disadvantages, tending to overdefine the project at an early stage, and the practical validity of the outcomes will depend heavily on the accuracy of the original guesses.

The early 'setting' of assumptions can be illustrated from irrigation planning. Here, the cropping pattern is usually tentatively specified at an early stage and then used by engineers in canal design work, by agriculturists in variety selection and by economists for work on farm management and marketing. The assumptions, however tentative they are, quickly become firm because of the immense amount of work which is based upon them. Woe betide the economist who claims later that one crop in the tentative cropping pattern is unprofitable, or that farm power constraints preclude sowing a crop on the assumed date, if this finding is made after the halfmonthly crop water requirements have been estimated or canal designs and operating regimes determined. Practical experience in project planning teams suggests that it is not only projects that, once started, are largely irreversible; working assumptions are, too.

In these circumstances much of the subsequent detailed survey work and calculation, undertaken on the basis of tentative assumptions, supposedly to 
identify and appraise constraints and develop alternatives, is redundant and too detailed. Its function is to justify ex post, not to identify alternatives ex ante. If a new approach is to be adopted, with early planning assumptions genuinely tentative, then RRA could come into its own as an important part of the new methodology. Indeed, if a cost-effective iterative design process is to be followed in practice-and not merely advocated in principle-and if sensitivity analysis is to be used throughout the planning period, then rapid appraisal will be essential for agriculturists, engineers, cconomists and all other participants.

\section{STATISIICAL BARKIERS}

Rapid appraisal with a broad focus is likely to offend statistical norms for sample size. This situation has a disproportionate impact on the professional regard for the output of RRA because there are biases in prestige and status. (See Moore ${ }^{55}$ for a vigorous attack on these lines). The manipulation of numbers has the status of arcane mathematical mystery which allows statisticians, its high priests, to criticise, veto, validate or amend the research of others. Rigid and unimaginative statistical training can inflict a sort of brain damage, instilling the importance of the central limit theorem and Techebycheff's inequality, but failing to give guidance on practical questions such as how to select a sample when you do not have a sampling frame or enought time to study all in the sample.

Problems with sampling are worth elaborating since they lie at the heart of the unease of the professional with his 'skinny' survey. Rural areas present more difficult, expensive and time-consuming survey problems than urban studies. In order to provide maximum insight with scarce resources and time, compromises have to be made in selecting the sample size, the scope of the survey and the accuracy of measurement. As a result, most investigators adopt purposive, rather than random, sampling procedures. Despite the fact that purposive sampling is the norm, even in many scholarly investigations, few texts on survey methodology discuss this or give guidance on the issues raised by non-random sampling. For example, Parel et al. ${ }^{11}$ do not mention non-random technique experience with field data.

There are four major problems which arise in a rapid rural appraisal which often prevent random sampling being used. First, the target population is scattered over a wide area and access may be difficult. Secondly, the variability of the factors to be studied is either very large or unknown and a population frame may not be available. Thirdly, an appraisal generally aims to cover not one but many factors and a sample size which is appropriate for one factor may be too small or too big for others. Fourthly, much of the data to be collected is of a type for which rapid or superficial collection is likely to lead to massive measurement errors. Agricultural labour use is (arguably) an example where a rapid survey will give inaccurate and possibly unintelligible information which can only be corrected by repeated visits or short surveys at predetermined peak periods. 
A good survey has a small sampling error and a minimum measurement error and investigates several dimensions of the problem. This ideal can only be achieved with ample resources of time, manpower, transportation and so forth. Given limited resources and high opportunity costs, it may be necessary to restrict coverage by examining fewer aspects of the village economy and to allocate the available resources to obtaining more accurate information. This may require repeated visits. An alternative is to reduce the sample size, to save time, to below that number which is considered to be the minimum required for an acceptable level of sampling error. In planning and evaluation, assessing the merit of such trade-offs presents important decisions for the investigator. The issues are illustrated diagrammatically in Fig. 1. If

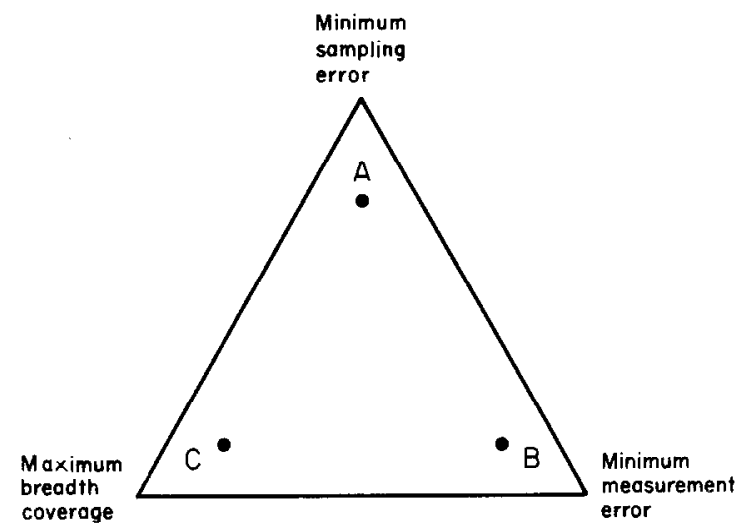

Fig. 1. Multiple goals in survey design.

a research design is chosen which strcsses minimising sampling error (point ' $A$ ') this will imply less resources to obtain accurate records and some restriction in the breadth of coverage. Generalising, the strategies used by statisticians tend to be 'A', those of economists and technicians near ' $\mathrm{B}$ ' and those of sociologists and anthropologists near ' $\mathrm{C}$ '. Wherever an investigator is forced by time or resource limitations to make a choice between measurement error and sampling error it is only likely to be feasible to reduce sample size. In this circumstance the ideal of a random sample is likely to be unattainable and some purposive selection is required. Various devices, such as stratified sampling, cluster sampling and multi-stage sampling, can improve the efficiency of random sampling. However, at best, investigators are often forced to draw tentative conclusions from a few case studies or non-random samples with obvious limitations on the general applicability of the findings.

Indeed, in practice, appraisal and planning often follow other, even less satisfactory, paths. All too often policy has to be determined with virtually no field insight, or before a survey has been processed and analysed. 
In such circumstances the practical alternative of rapid assessment of purposively selected case studies, with their acknowledged limitations, often proves superior to either casual empiricism or the delayed results of a large and more conventional survey.

How much the balance of advantage lies with RRA depends on its purpose, local conditions and the degree of urgency. In general, our view is that there are gains to be made through shifts towards few case studies in depth rather than large samples with shallow coverage. This applies especially in ex post evaluation which seeks to unravel the causes of observed change. But it must be emphasised that the choice of optimal location within the triangle-the trade-offs between sampling, coverage and precision-has to be determined case by case.

Case studies and less formal local investigations require senior staff to spend more time in the field. Other objections to RRA, on the basis of lack of statistical rigour and the like, may then be reinforced by biases of class and convenience on the part of those who dislike fieldwork or find it demeaning. Survey data can be refined and analysed safely in the comfort of an urban office without the rude shocks of rural exposure. This urban and elite processing of data collected by others has led M. N, Srinivas ${ }^{14}$ to remark on 'The division of labour between the theoreticiananalyst and the fact gatherer', the latter constituting a "helot class" which does the rural work of investigation and enumeration, allowing the analyst to work away without the inconvenience of contact with the rural reality.' (pp. 1390 and 1389). It is not beyond human frailty to prefer methods of investigation and analysis which avoid discordant contacts. And numbers are more manageable than people.

\section{A NEW PROFESSIONALISM}

This argument--and the papers in this issue - are part of a search for professional values based on the rigour of cost-effectiveness. Traditional professionalism is often seen as embodied in rigour of a different sort, without trade-offs with cost and timeliness. Often, too, it limits investigations to one or a few methods only, and those which are amenable to statistical analysis, although usually time-consuming and expensive, are often professionally safer and tend to predominate. The final paragraph of Collinson's paper is significant in this connection. In the appraisal procedure which he describes, the formal verification survey which comes at the end of the sequence has, in practice, always verified the earlier findings. It may therefore be superfluous. But the numbers produced by this formal verification survey are the only 'hard evidence' produced by the diagnostic process and 'extremely important' in persuading the Establishment that there is a need to understand small farmers as a prerequisite to relevant research and development. Our conclusion, however, is that if a relatively expensive and time-consuming verification is only needed to persuade the Establishment, then the valucs of the Establishment are a luxury and must be challenged and changed. 
There are likely to be serious difficulties in persuading decision-makers that imprecise estimates or unquantified judgements based on RRA are superior to conventional and formal (even if spurious) accuracy and detail. It will perhaps always be a struggle to argue, however valid the case, that it is better to be vaguely right than precisely wrong.

The papers in this issue suggest that efficient appraisal will often be informal and eclectic. It is partly the informality which permits the electicism. It can be precisely because there is no irreversible commitment to one method that a medley of methods can be chosen on the run, as appropriate. It is as though the investigator has not one bright, narrow beam, but instead a large number of less intense lights which can illuminate different aspects of the whole. Combinations of methods seeing the same things from different angles and in different ways-add dimensions and insights. Combinations of methods can also be used to eliminate questions which do not need to be asked. Much of the skill of the experienced researcher lies in judgements about questions which do not need to be asked. There is an implicit procedure in the sequence of investigations. The need, often, is to formalise this into a process which, whilst still simple and quick, can be used by investigators with less experience. It is here that the methods described by Hildebrand, Collinson and Bartlett and Ikeorgu have a special contribution to make.

There remains a central paradox. Cost-effectiveness, as we have argued, is often to be found in trade-offs between amount, relevance, accuracy, and especially timeliness, to enable information to be used. The stress is then on rapidity in appraisal. But hurry is itself a major source of bias and error. Much of the rationale for rapid appraisal is that it should release time from routine, stereotyped and repetitive actions (enslavement to the questionnaire, or to precise and frequent physical measurements) which can then be devoted to more open and useful investigation. If the result of rapid appraisal methods were merely the obverse of Parkinson's law, making work shrink to fit the short time available, then many of the benefits would have been lost. The key to good rapid appraisal is not just being observant, sensitive and eclectic and following up on leads; it is also-and crucially - allowing enough time to do so. As Swift especially stresses there are limits to the rapidity with which complex issues can be explored.

The range of approaches and techniques available for rapid appraisal may, for the very reason of its informality, not be written up and recognised. Each problem requires its own mix and sequence, and this cannot always be foreseen. Any list might include:

(i) Offsetting biases. Through introspection, identifying likely cognitive biases (in rural development tourism, in questionnaire design, in types of information excluded by a method) and then deliberately offsetting those biases.

(ii) Observing directly. Being observant, looking for the unusual, and following 
up on serendipity. Experiencing the same phenomenon in different wayson the ground, from the air, through participant observation in different places and at different times.

(iii) Tapping existing knowledge. Searching for and studying existing reports and records, finding key informants (social anthropologists, scientists, those with indigenous technical knowledge). Using panels of informants, or an existing sample about which information is already available.

(iv) Interviewing inventively. Abjuring the fixed questionnaire, except for limited purposes of survey (Bartlett and Ikeorgu) or verification (Collinson), and instead using guided interviews (Collinson, Ellman, Carruthers ${ }^{35}$ ) and group interviews (e.g. Gordon ${ }^{45}$ ).

(v) Using proxy indicators. Identifying indicators (often perhaps suggested by rural people) which reflect the interdependence and covariance of different factors, as in natural resources appraisal (Stocking and Abel).

(vi) Combining the insights of different disciplines. Planning the interaction of disciplines in appraisal to speed and improve the insights gained and the ideas generated (Hildebrand, Collinson).

(vii) Combining different methods and sources. Comparing and complementing information from different sources.

This last deserves special attention. Indigenous technical knowledge (ITK) (IDS, ${ }^{6}$ Brokensha et $a .^{2}$ ) and modern scientific knowledge have complementary strengths and weaknesses (Richards ${ }^{22}$ ). The strength of ITK may often lie in categories and knowledge which are utilitarian and based on observation over long periods, whilst that of modern scientific knowledge is based more on precise measurement and specialised techniques of observation. But this separation is not absolute, and Swift describes involving pastoralists themselves as enumerators in surveys of family labour use, household transactions and animal milk production. He also suggests that environmental degradation might be monitored by combining remote sensing from satellites with pastoralists' own knowledge and observation of vegetation and its changes. In ways such as these, many possibilities for inventiveness in rural appraisal are opening up. The hope is that natural and social scientists will be free enough from the constraining and negative aspects of their professional conditioning to be able to explore, develop and use now approaches and establish thosc that prove costeffective as professionally respectable.

CONCLUSION

In emphasising the need for eclecticism, inventiveness and versatility, and in questioning some conventional values in research, especially in statistics, we do not 
undervalue traditional standards and methods where they fit well. We are not advocating a new sloppiness. It is all too easy to be rapid and wrong and, as Swift points out, in pastoral environments there is still much ignorance which can only be removed by sustained and careful research over long periods. What we are advocating is the recognition and development of rapid and data-sparing appraisal as a legitimate and valued activity. In a modest way, this issue shows that its techniques can be written about. We hope this will encourage others who use and develop similar approaches to rural appraisal to be bold in writing up and publishing their methods and results; for in that way more can share the experience being gained by the many in different disciplines who are converging independently on this same new professional ground.

\section{REFERENCES}

1. Brammer, H., Some innovations don't wait for experts, Ceres 74, 13(2) (March-April, 1980), pp. 24-28.

2. Brokensha, D. W., Warren, D. M. \& Werner, O. (Eds.), Indigenous knowledge systems and development, University Press of America, Maryland, 1980.

3. Byerlee, D., Biggs, S., Collinson, M., Harrington, L., Martinez, J. C., Moscardi, E. \& Winkleman, D., On-farm research to develop technologies appropriate to farmers. Paper presented at the Conference of the International Association of Agricultural Economists, Banff, Canada, September, 1979.

4. Chambers, R., Rapid rural appraisal: Rationale and repertoire, IDS Discussion Paper 155, Institute of Development Studies, University of Sussex, Brighton, 1980.

5. Chambers, R., Rural poverty unperceived: Problems and remedies, World Bank Staff Working Paper No. 400, World Bank, Washington, DC, 1980.

6. IDS, Rural development: Whose knowledge counts?, IDS Bulletin 10, 2, Institute of Development Studies, Universily of Sussex, Brighton, UK, January, 1979.

7. Ilchman, W. F., Decision rules and decision roles, The African Review, 2(2) (1972), pp. $219-46$.

8. OXFAM, Field Directors' Handbook (Revised February, 1980), OXFAM, Banbury Road, Oxford, UK.

9. PACEY, A., Taking soundings in developing corrmunities: An approach to the information needs of rural development workers, district officials, and health service staff, WHO, Geneva, 1981.

10. Pacey, A., Chambers, R. \& Longhurst, R. (Eds.), Seasonal dimensions to rural poverty, Frances Pinter, London, 1981.

11. Parel, C. P., Caldito, G. C., Ferrer, P. L., Deguzman, G. C., Sinsroco, C. S. \& Tuin, R. H., Sampling design and procedures, ADC, Singapore, 1975.

12. Senaratne, P. F., Economic development and the sociological consultant: A Sri Lankan experience. Paper for the Social Science Research Council Workshop at University of Sussex, 1-2 July, 1978.

13. Snow, C. P., The two cultures and the scientific revolution, The Rede Lecture 1959, Cambridge University Press, 1959.

14. SRinivas, M. N., Village studies, participant observation and social science research in India, Economic and Political Weekly, 10(33-35) (1975), pp. 1387-93.

15. Srinivas, M. N., Shah, A. M. \& Ramaswamy, E. A. (Eds.), The fieldworker and the field: Problems and challenges in sociological investigation, Oxford University Press, Bombay, Calcutta, Madras, 1979.

16. WHO, Rapid village nutrition survey technique, WHO Regional Office for Africa, AFR/NUT/84, 1977.

Papers presented to the Preliminary Workshop on Rapid Rural Appraisal held at the Institute of Development Studies, 26-27 October, 1978.

17. BARKer, D., Appropriate Methodology: An Example Using a Traditional African Board Game to Measure Farmers' Attitudes and Environmental Images. 
18. Belshaw, D. G. R., Village Viability Assessment Procedures in Tanzania: Decision-Making with Curtailed Information Requirements.

19. Clay, E. J., Direct and Indirect Methods of Observation in Rapid Rural Appraisal.

20. Jackson, Cecile, Sattar, Mandal \& Carruthers, I., Notes on Rapid Land Ownership and Management Studies.

21. Longhurst, R., Rural Stratification and Resource Allocation: Some Thoughts on Deriving Most Useful Information in Short Periods of Time

22. Richards, P., Geography is a Bottle of Heineken Lager Beer. How to be the Most Boring Person in Development Planning and Still get Your Facts Wrong.

23. SANDFORD, S., Some Miscellaneous Thoughts

24. SANDFORD, S., Situations and Trends with Pastoral People and Livestock.

25. SwIFT, J., Notes on Rapid Rural Appraisal in Dry Pastoral Areas of West Africa.

26. Wood, G., The Epistemology of Rapid Rural Appraisal?

Papers presented to the Conference on Rapid Rural Appraisal held at the Institute of Development Studies, 4-7 December, 1979

27. Abel, N. \& Stocking, M., Rapid Aerial Survey Techniques for Rural Areas.

28. Bairacharya, D., Firewond Consumption in the Nepal Hills: A Comparison of the Annual Recall and the Weekly Recorded Data.

29. Barnett, A., A Personal View of the First IDS Workshop.

30. Bartlett, C. D. S. \& Ikeorgu, J. E. Selecting Innovations for Small Farmers.

31. Bfishaw, D. G. R. Theoretical Foundations of Data-Fconomising Appraisal Procedures, with Applications to Rural Development Planning.

32. Biggs, S. D., Timely Analysis in Programmes to Generate Agricultural Technologies.

33. Boxall, R. A., The Use of Rapid Appraisal Methods in the Assessment of Post-Harvest Losses.

34. Rridrfr, G. A., Rapid Project Appraisal (Original July, 1977).

35. Carruthers, I., A Mental Construct for Unstructured On-Farm Interviews.

36. Carruthers, I., Breadth, Depth or Replications?-Sampling Problems with Insufficient Time, Money or Background.

37. Carruthres, I, Too Iate to Change. The Reality of Multi-disciplinaty Planning in Irrigation.

38. Clay, E. J., Farm Management Studies and the Decision Process (extract from 'Information and Research Inputs into Agricultural Policy Formation', Ministry of Agriculture and Forests Dacca, September 1979).

39. Cot.t.rnson, M., Inderstanding Small Farmers

40. Conlin, S., Baseline Surveys: An escape from Thinking about Research Problems and, Even More, A Refuge from Actually Doing Anything.

41. Ellman, A., Cost Effectiveness of Rapid Appraisal for Rural Project Preparation.

42. Eyben, Rosalind, Rapid Appraisal in Non Formal Education: An Account of an On-going Research Experience with a United Nations Project.

43. Fallon, P., Comments on Mick Moore's 'Denounce the Gang of Statisticians, etc.'

44. Feuerstein, Marie Therese, Establishing Rapport (an informal paper for discussion).

45. Gordon, Gill, Finding out About Child ( $0-5$ years) feeding Practices.

46. GORDON, GILL, The Hungry Season in the Savanna of West Africa.

47. HAY, R. W., Towards a Methodology of 'Rapid Rural Assessment'? or 'Can Dirty Methods be Made Cleaner'? (an informal paper for discussion).

48. Hildebrand, P. E., Summary of the Sondeo Methodology I Ised by ICTA(1) 1. Instituto de Ciencia y Technologia Agricolas, Guatemala.

49. Hildebrand, P. E., Comments about Multidisciplinary Team Efforts (This paper originally appeared as an appendix to Peter E. Hildebrand's 'Motivating Small Farmers to Accept Change'. Paper for the Conference on Integrated Crop and Animal Production to Optimise Resource Utilisation on Small Farms in Developing Countries. Bellagio, 18-23 October, 1978. The references are those of the original paper).

50. Honadle, G., Rapid Reconnaissance Approaches to Organisational Analysis for Development Administration.

51. Howell, J., Appraising Organisations: Purpose, Method and Cost-Effectiveness.

52. Howes, M., Stratifying a Rural Population: Trade-offs between Accuracy and Time.

53. Longhurst, R., Assessing Economic Stratification in Rural Communities.

54. MoOre, M., Beyond the Tarmac Road: A (Nut)Shell Guide for Rural Poverty Watchers.

55. Moore, M., Denounce the Gang of Statisticians. Struggle Against the Sample Line. Unite the Researching Masses Against Professional Hegemony. 
56. The OXFAM Field Directors' Handbook: Three Appendices. What to look for when visiting projects. Checklists on aspects of the participation of women in development projects. Social surveys.

57. PACEY, A., Rural Appraisal in Sanitation Programmes: A Technology Case-Study.

58. Payne, P. R., Assessment of Nutrition Problems: Who Do we Look at and What do we Measure?

59. Richards, P., Appraising Appraisal.

60. Stares, R., Rapid Rural Appraisal and the Needs of a Non-governmental Development Agency: Some thoughts from OXFAM.

61. Stern, P. H., Small-Scale Technology in Water Resources Development.

62. Stocking, M., ABel, N., Ecological and Environmental Indicators for the Rapid Appraisal of Natural Resources.

63. Taylor, A. J., From Nicaragua: Experiences with a Model for Assessing Small Scale Rural Development Projects.

64. Walker, G., Notes on Rapid Appraisal of the Utilisation of Rural Health Care Services.

65. Wood, G. D., The Social and Scientific Context of RRA.

Papers Tabled (in limited supply)

66. Chen Lincoln, C., Alauddin Chowdhury, A. K. M. \& Huffman Sandi, Classification of EnergyProtein Malnutrition by Anthropometry and Subsequent Risk of Mortality.

67. OXFAM Field Directors' Handbook: Section 8: Project Design and Assessment. (The Handbook is a very substantially revised third edition of approximately 450 pages with a complete set of guidelines covering the full range of development activities for OXFAM, including agriculture, health, and social development, also welfare and disaster relief. Available at US $\$ 20$ from Oxfam, Oxford.)

68. WHO, Selected Health and Health-related Socio-economic Indicators for Measuring Health Status and Evaluating Health Care, Interregional Meeting on the Development of Health Programme Evaluation, Geneva, 9-14 July, 1979.

69. WHO, Rapid Village Nutrition Survey Technique, Regional Office for Africa.

\section{Papers subsequent to the Conference}

70. Alderson, J., Summary Report of a Conference on Rapid Rural Appraisal held at IDS, University of Sussex.

71. Alderson, J., Summary Report of a Conference on Rapid Rural Appraisal held at IDS, University of Sussex.

72. Chambers, Robert, Rapid Rural Appraisal: Rationale and Repertoire, IDS Discussion Paper 155, Institute of Development Studies, University of Sussex, Brighton, UK.

73. Conlin, S. \& Wiggins, S., Rapid Rural Appraisal: A Review of the December 1979 Conference and its Papers. 